\title{
Distribution of ABO Blood Group and Major Cardiovascular Risk Factors with Coronary Heart Disease
}

\author{
Santanu Biswas, ${ }^{1}$ Pradip K. Ghoshal, ${ }^{2}$ Bhubaneswar Halder, ${ }^{2}$ and Nripendranath Mandal $^{1}$ \\ ${ }^{1}$ Division of Molecular Medicine, Bose Institute, P-1/12 CIT Scheme VIIM, Kolkata 700054, India \\ ${ }^{2}$ Department of Cardiology, N.R.S. Medical College \& Hospital, 138 A.J.C. Bose Road, Kolkata 700014, India \\ Correspondence should be addressed to Nripendranath Mandal; mandaln@rediffmail.com
}

Received 24 April 2013; Revised 11 July 2013; Accepted 17 July 2013

Academic Editor: Sudhish Mishra

Copyright (c) 2013 Santanu Biswas et al. This is an open access article distributed under the Creative Commons Attribution License, which permits unrestricted use, distribution, and reproduction in any medium, provided the original work is properly cited.

\begin{abstract}
The purpose of this study is to establish whether $\mathrm{ABO}$ blood group is related to coronary heart disease in an individual in Asian Indian Bengali population of eastern part of India. Two hundred and fifty (250) CHD patients and two hundred and fifty (250) age and sex matched healthy subjects were enrolled in the study. ABO blood group distribution in patients was compared with control group. Frequency of major cardiac risk factors was determined to find any correlation between blood groups and cardiovascular risk factors. The distribution of $\mathrm{ABO}$ blood groups in patients versus control group was $\mathrm{A}$ in 24.00 versus $21.60 \%$, B in 30.80 versus $32.40 \%$, $\mathrm{O}$ in 38.40 versus $21.60 \%$, and $\mathrm{AB}$ in 6.80 versus $24.40 \%$. The analysis showed significant difference in frequency of $\mathrm{O}$ $(\mathrm{OR}=1.857,95 \% \mathrm{CI}=1.112-3.100, P=0.018)$ and $\mathrm{AB}(\mathrm{OR}=0.447,95 \% \mathrm{CI}=0.227-0.882, P=0.020)$ blood group between healthy controls and CHD individuals. Our results may suggest that the AB blood group decreases the risk of CHD in healthy controls, and it might be due to the higher concentration of high density lipoprotein cholesterol (HDL-c), while the O blood group increases the risk of CHD due to lower HDL-c levels in Bengali population of eastern part of India.
\end{abstract}

\section{Introduction}

Coronary heart disease (CHD) is a multifactorial disease. The etiology of CHD is complex and appears to involve interactions between genetic and environmental factors. Blood is an individual's complete and unchangeable identity. Although almost 400 blood group antigens have been reported, the $\mathrm{ABO}$ and $\mathrm{Rh}$ have been recognized as the major clinically significant blood group antigens [1]. Research on $\mathrm{ABO}$ group system has been of immense interest, due to its medical importance in different diseases [2-7], though the explanation for the association between $\mathrm{ABO}$ blood groups and some disease is still unclear. Clinical studies have shown that individuals of the A phenotype blood group are more susceptible to cardiovascular disease $[8,9]$. In British men, the incidence of ischemic heart disease is higher in patients with blood group A [10]. Likewise, in the Hungarian population, again blood group $\mathrm{A}$ is more common in patients with CHD [11]. In a most recent study carried out in Copenhagen, Denmark, the Lewis blood phenotype Le (a-b-) was found to be associated with an increased risk for CHD in men; this appears independent of conventional cardiovascular risk factors like smoking, obesity, diabetes mellitus, high cholesterol, triglycerides, and so forth [12].

The present study was designed to explore the relation between $\mathrm{ABO}$ blood group and coronary heart disease in Asian Indian Bengali population of eastern part of India. We also examined the relation between $\mathrm{ABO}$ blood group and cardiovascular risk factors.

\section{Methods}

All subjects are Indian Bengali adults. The criteria for selecting the patients $(n=250)$ and controls $(n=250)$ have been presented in detail previously [13]. Briefly, patients having typical angina and evidence of ischemia or infarction after electrocardiographic study, tread mill test, stress echo 
and echocardiographic study; on the other hand, controls comprised the spouses, neighbors, and people from same work place of the patients, with the same sociocultural background, in whom the clinical history, the objective search for signals of $\mathrm{CHD}$, and the electrocardiographic as well as echocardiographic examinations did not suggest the presence of that disease. All patients and controls with ancestral origin were from the Bengali eastern part of India. All patients were admitted to the hospital within 12 hours of the onset of chest pain. Blood samples for biochemical analysis were taken at the time of admission. Blood samples were collected by vein puncture into vacuum tubes containing EDTA. Any patients or controls found to have taken any lipid-lowering drugs were excluded from the study. Plasma samples were processed on the day of sample collection by centrifugation at $3000 \mathrm{rpm}$ for $10 \mathrm{~min}$ at room temperature using tabletop centrifuge (Remi Pvt. Ltd., Mumbai, India), divided into aliquots, and stored in cryovials at $-80^{\circ} \mathrm{C}$ until further analysis. Patients and controls were fully informed of the aim of this study. All subjects included gave their informed consent to participation in the study. The study was approved by the ethics committee of the institute involved.

Standard slide method was adopted: a drop of each of the monoclonal antisera (Anti-A, Anti-B and Anti-D) (manufactured by Agappe Diagnostics Ltd., Kerala, India) was taken on glass slides. The blood cells subjects of whose blood group is to be determined were mixed with each blood separately with the help of separate glass rods. Blood groups were determined on the basis of agglutination reaction within 5 minutes of mixing. Total cholesterol (TC) was determined enzymatically using CHOD/POD-Phosphotungstate reagent. High density lipoprotein cholesterol (HDL-c) was determined with CHOD/POD-Phosphotungstante reagent (Accurex Biomedical Pvt. Ltd., India), after precipitation with phosphotungstic acid. Triglyceride (TG) was determined using GOP-POD reagent (Accurex Biomedical Pvt. Ltd., India). Besides values of low density lipoprotein cholesterol (LDL-c) were estimated using the formulae LDL-c $=$ TC $-($ HDL-c + FTG/5) [14].

After the completion of each experiment, the data were recorded on predesigned proforma and managed with Microsoft Excel software. Data entry was double checked for any human error. All calculations were performed using SPSS version 10.0 software package for Windows. Continuous variables are expressed as mean (standard deviations) and as percentages for categorical variables. Comparisons between groups were done using unpaired Student's $t$-test or chisquare $\left(\chi^{2}\right)$ test as appropriate. An allele frequency of the antigens was computed by application of the Hardy-Weinberg Law [15] on the basis of the number of subjects with different blood groups. ABO differences in cardiovascular risk factors were examined using post hoc analysis, after correcting the $P$ value for multiple comparisons by using Bonferroni's correction. The association between different parameters and risk of CHD was examined by estimating odd ratios (ORs) with corresponding 95\% confidence intervals (CIs), using univariate logistic regression analysis. Multivariate analysis was performed using multiple logistic regression (Enter method) to assess the independent adjusted relationship
TABLE 1: Characteristic of Asian Indian Bengalee population in eastern part of India in the case and control groups.

\begin{tabular}{lccc}
\hline Variable & $\begin{array}{c}\text { Case } \\
(N=250)\end{array}$ & $\begin{array}{c}\text { Control } \\
(N=250)\end{array}$ & $P$ value \\
\hline $\begin{array}{l}\text { No. }(\%) \text { of } \\
\text { smokers }\end{array}$ & $150(60 \%)$ & $70(28 \%)$ & $<0.0001$ \\
$\begin{array}{l}\text { No. }(\%) \text { of } \\
\text { alcohol users }\end{array}$ & $61(24.4 \%)$ & $35(14 \%)$ & 0.003 \\
$\begin{array}{l}\text { No. }(\%) \text { of } \\
\text { cases with } \\
\text { hypertension }\end{array}$ & $119(47.6 \%)$ & $84(33.6 \%)$ & 0.001 \\
$\begin{array}{l}\text { No. }(\%) \text { of } \\
\text { cases with }\end{array}$ & $81(32.4 \%)$ & $38(15.2 \%)$ & $<0.0001$ \\
$\begin{array}{l}\text { family history } \\
\text { WC (cm) }\end{array}$ & $87.24(6.37)$ & $85.28(5.30)$ & $<0.0001$ \\
$\begin{array}{l}\text { TC }(\mathrm{mg} / \mathrm{dL}) \\
\text { TG }(\mathrm{mg} / \mathrm{dL})\end{array}$ & $191.11(40.37)$ & $168.51(42.83)$ & $<0.0001$ \\
$\begin{array}{l}\text { HDL-c } \\
(\mathrm{mg} / \mathrm{dL})\end{array}$ & $28.81(7.28)$ & $34.60(8.52)$ & $<0.0001$ \\
$\begin{array}{l}\text { LDL-c } \\
(\mathrm{mg} / \mathrm{dL})\end{array}$ & $125.49(37.60)$ & $105.62(37.89)$ & $<0.0001$ \\
\hline
\end{tabular}

Continuos variable are expressed as mean (SD) and compared by Student's $t$-test. Categorical variables were expressed as percentage (\%) and compared by chi-square test.

TC: total cholesterol, SD: standard deviation, TG: triglycerides, HDL-c: high density lipoprotein cholesterol, LDL-c: low density lipoprotein cholesterol, WC: waist circumference.

between different variables and CHD with independent variables being those with $P \leq 0.05$ in univariate logistic regression analysis. The $P$ value $<0.05$ was considered statistically significant.

\section{Results}

During the period of this study, April 2009 to February 2011, $250 \mathrm{CHD}$ patients and 250 healthy controls, participated in this study. Females constituted $18.4 \%$ of the cases and $16.8 \%$ of the controls and males constituted $81.6 \%$ of cases and $83.2 \%$ of the controls $(P>0.05)$. No significant difference was observed in mean age between cases (mean: 54.71 years) and controls (mean: 54.49 years) $(P=0.375)$.

As shown in Table 1, smoking, being an alcohol user, hypertension, family history, and increased waist circumference were highly prevalent in the group with $\mathrm{CHD}$ as compared to control. The mean value of TC, LDL-c, and TG was significantly higher in CHD patient compared to control; on the contrary, the mean value of HDL-c was significantly lower in patient than control.

In Table 2 the distribution of ABO blood types in patients with $\mathrm{CHD}$ and controls is shown. Blood group $\mathrm{O}$ is more common $(38.40 \%)$ in patients than controls $(21.60 \%)(P<$ $0.0001)$. Blood group $A$ is also found more often in patients (24.00\%) than controls $(21.60 \%)(P=0.522)$. But in blood group $\mathrm{AB}$, the controls are more numerous $(24.40 \%)$ than patients $(6.80 \%)(P<0.0001)$. In blood group B also, the controls outnumber $(32.40 \%)$ the patients $(30.80 \%)(P=$ 
TABLE 2: Distribution of the ABO blood types in patients with CHD and controls.

\begin{tabular}{|c|c|c|c|c|c|c|c|c|c|}
\hline \multirow{2}{*}{ Sample } & \multirow{2}{*}{$n$} & & \multicolumn{4}{|c|}{ Phenotype frequency } & \multicolumn{3}{|c|}{ Allele frequency } \\
\hline & & & A & $\mathrm{B}$ & $\mathrm{O}$ & $\mathrm{AB}$ & $\mathrm{A}$ & $\mathrm{B}$ & $\mathrm{O}$ \\
\hline \multirow{2}{*}{ Patients } & 250 & Abs. no. & 60 & 77 & 96 & 17 & \multirow{2}{*}{0.193} & \multirow{2}{*}{0.238} & \multirow{2}{*}{0.567} \\
\hline & & $\%$ & 24.00 & 30.80 & 38.40 & 6.80 & & & \\
\hline \multirow{2}{*}{ Controls } & 250 & Abs. no. & 54 & 81 & 54 & 61 & \multirow{2}{*}{0.265} & \multirow[t]{2}{*}{0.337} & \multirow{2}{*}{0.398} \\
\hline & & $\%$ & 21.60 & 32.40 & 21.60 & 24.40 & & & \\
\hline
\end{tabular}

TABLE 3: Distribution of major cardiovascular risk factors in all samples $(n=500)$ in accordance with ABO blood groups.

\begin{tabular}{|c|c|c|c|c|c|}
\hline \multirow{2}{*}{ Variables (mean (SD)) } & \multicolumn{4}{|c|}{ Blood group } & \multirow{2}{*}{ Test for heterogeneity ${ }^{1}$} \\
\hline & $\mathrm{AB}(n=78)$ & $\mathrm{A}(n=114)$ & $\mathrm{B}(n=158)$ & $\mathrm{O}(n=150)$ & \\
\hline TC (mg/dL) & $174.08(44.52)^{2}$ & $181.24(36.29)$ & $185.28(49.77)$ & $174.96(38.43)$ & $P=0.117$ \\
\hline TG (mg/dL) & $163.11(39.02)$ & $159.24(64.28)$ & $164.01(66.02)$ & $161.38(59.03)$ & $P=0.928$ \\
\hline HDL-c (mg/dL) & $36.65(12.04)$ & $30.81(5.78)^{5}$ & $32.13(7.39)^{5}$ & $29.56(8.11)^{5}$ & $P<0.0001$ \\
\hline LDL-c (mg/dL) & $104.80(40.71)$ & $118.58(32.29)$ & $120.34(44.05)^{4}$ & $112.78(35.79)$ & $P=0.025$ \\
\hline $\mathrm{WC}(\mathrm{cm})$ & $85.55(4.03)$ & $86.62(6.93)$ & $86.04(6.08)$ & $86.56(5.72)$ & $P=0.557$ \\
\hline Smoker & $25(32.1 \%)^{3}$ & $41(36 \%)$ & $78(49.4 \%)$ & $78(52 \%)^{4}$ & $P=0.007$ \\
\hline Alcohol user & $9(11.5 \%)$ & $40(35.1 \%)^{5}$ & $36(22.8 \%)$ & $14(9.3 \%)$ & $P<0.0001$ \\
\hline Hypertension & $25(32.1 \%)$ & $46(40.9 \%)$ & $66(41.8 \%)$ & $67(44.7 \%)$ & $P=0.457$ \\
\hline Family history & $8(10.3 \%)$ & $27(23.7 \%)$ & $41(25.9 \%)$ & $43(28.7 \%)^{4}$ & $P=0.037$ \\
\hline
\end{tabular}

${ }^{1}$ Derived from analysis of covariance that evaluated the associations between major cardiovascular risk factors (dependent factor) and blood group (independent factor), after adjustment for age (in years) and sex.

${ }^{2}$ Mean (SD) (all such values).

${ }^{3}$ Number (percentage in individual group) (all such values).

${ }^{4,5}$ Significantly different from AB blood group (ANOVA with Bonferroni's correction): ${ }^{4} P<0.05,{ }^{5} P<0.01$.

A indicates A blood group; B indicates B blood group; O indicates O blood group; AB indicates AB blood group; TC: total cholesterol; TG: triglycerides; HDLc: high density lipoprotein cholesterol; LDL-c: low density lipoprotein cholesterol; WC: waist circumference.

0.271). The allele frequencies in both the patients and the controls are in order $\mathrm{A}<\mathrm{B}<\mathrm{O}$.

We examined the contribution of major cardiovascular risk factors in subjects with $\mathrm{ABO}$ blood groups to all 500 patients (Table 3). We found from the analysis that HDL$c$ and LDL-c had significantly different mean value in the blood groups. The mean value of HDL-c was highest among $\mathrm{AB}$ group $(36.65 \mathrm{mg} / \mathrm{dL})$ and in $\mathrm{O}$ group was lowest $(29.56 \mathrm{mg} / \mathrm{dL})$ compared to other groups. But on the other hand, the LDL-c concentration was higher in $\mathrm{O}$ group (112.78 mg/dL) than AB group (104.80 mg/dL). In this analysis we also found that $28.7 \%$ of blood group $\mathrm{O}$ population had CHD in their family history. Post hoc analysis revealed significant difference of $\mathrm{ABO}$ blood group. In particular, compared with $\mathrm{AB}$ blood group, the $\mathrm{A}, \mathrm{B}$, and $\mathrm{O}$ groups were associated with substantial decrease of HDL-c levels. With regard to smoking and family history, differences were significant when we compared O blood group with AB blood group. There was no such significant difference of LDL-c levels found when we compared the $\mathrm{AB}$ blood group and $\mathrm{O}$ blood group but significant difference was found only when we compared the B blood group with $\mathrm{AB}$ blood group.

In Table 4, the univariate analysis showed significant difference in $\mathrm{O}$ blood group between the patient and control groups $(\mathrm{OR}=2.263,95 \% \mathrm{CI}=1.525-3.357 . P<0.0001)$. In addition, a significant association was found between $A B$ blood group and CHD $(\mathrm{OR}=0.226,95 \% \mathrm{CI}=0.128-0.400$, $P<0.0001)$. No significant difference in blood groups $\mathrm{A}$
TABLE 4: Risk of coronary heart disease (CHD) by ABO blood group and other risk factors in the study patients as compared to study controls.

\begin{tabular}{lccc}
\hline Variables & Odd ratio & $95 \%$ CI & $P$ value \\
\hline $\mathrm{A}$ & 1.146 & $0.754-1.742$ & 0.523 \\
$\mathrm{~B}$ & 0.834 & $0.574-1.212$ & 0.341 \\
$\mathrm{O}$ & 2.263 & $1.525-3.357$ & 0.000 \\
$\mathrm{AB}$ & 0.226 & $0.128-0.400$ & 0.000 \\
$\mathrm{TC}$ & 0.987 & $0.982-0.991$ & 0.000 \\
$\mathrm{TG}$ & 0.986 & $0.983-0.990$ & 0.000 \\
HDL-c & 1.102 & $1.073-1.132$ & 0.000 \\
LDL-c & 0.986 & $0.981-0.991$ & 0.000 \\
Smoker & 1.851 & $1.294-2.647$ & 0.001 \\
Hypertension & 1.795 & $1.251-2.576$ & 0.001 \\
Alcohol user & 1.983 & $1.253-3.138$ & 0.003 \\
WC & 0.945 & $0.916-0.974$ & 0.000 \\
Family history & 2.674 & $1.730-4.132$ & 0.000 \\
\hline
\end{tabular}

Odd ratio (OR) calculated by univariate logistic regression analysis. A indicates A blood group; B indicates $\mathrm{B}$ blood group; $\mathrm{O}$ indicates $\mathrm{O}$ blood group; $\mathrm{AB}$ indicate $\mathrm{AB}$ blood group; TC: total cholesterol; TG: triglycerides; HDL-c: high density lipoprotein cholesterol; LDL-c: low density lipoprotein cholesterol; WC: waist circumference.

and $\mathrm{B}$ was observed between cases and controls $(P>0.05)$; other biochemical and conventional risk factors were also significantly associated with the disease. 
TABLE 5: Multivariate logistic regression analysis of different variables of coronary heart disease among Asian Indian Bengalee population in the eastern part of India.

\begin{tabular}{lccc}
\hline Variables & Odd ratio & $95 \% \mathrm{CI}$ & $P$ value \\
\hline TC & 0.990 & $0.984-0.996$ & 0.001 \\
TG & 0.990 & $0.985-0.994$ & $<0.0001$ \\
HDL-c & 1.097 & $1.063-1.132$ & $<0.0001$ \\
AB & 0.447 & $0.227-0.882$ & 0.020 \\
O & 1.857 & $1.112-3.100$ & 0.018 \\
Smoker & 1.340 & $0.897-2.003$ & 0.153 \\
Hypertension & 1.772 & $1.130-2.779$ & 0.013 \\
Alcohol user & 2.004 & $1.100-3.650$ & 0.023 \\
WC & 0.917 & $0.882-0.954$ & $<0.0001$ \\
Family history & 1.430 & $0.821-2.490$ & 0.206 \\
\hline
\end{tabular}

Odd ratio $(\mathrm{OR})$ calculated by multiple logistic regression analysis. $\mathrm{O}$ indicates $\mathrm{O}$ blood group, $\mathrm{AB}$ indicates $\mathrm{AB}$ blood group; TC: total cholesterol; TG: triglycerides; HDL-c: high density lipoprotein cholesterol; WC: waist circumference.

Multivariate analysis was performed including the variables which revealed statistically significant difference in the univariate analysis. In this analysis, LDL-c was set to be zero because it is redundant. In the end point of this analysis, $A B$ and $\mathrm{O}$ blood groups along with TC, TG, HDL-c, and other conventional risk factors (i.e., hypertension, being an alcohol user, and waist circumference) remained significant, but the smoking and family history lost their significance (Table 5).

\section{Discussions}

The ABO blood group system is the most important system for blood group compatibility. However, as suggested elsewhere, ABO blood group may have additional consequences on other factors that might also contribute to the risk of thrombosis [16, 17] and deserve additional investigation particularly to explain the CHD risk. The data generated in the present study may be useful for health planners, while making efforts to face the future health challenges in the region. In short, generation of a simple database of blood groups not only provides data about the availability of human blood in case of regional calamities but also serves to enable insight into possibilities of future burden of diseases.

In the present study, we determined the frequency of $\mathrm{ABO}$ blood antigens in CHD patients and healthy controls. Our result showed that the $\mathrm{AB}$ blood group decreases the risk of $\mathrm{CHD}$ in healthy controls, while the $\mathrm{O}$ blood group is more frequent in $\mathrm{CHD}$ patients and increases the risk of $\mathrm{CHD}$. The results obtained in this study show that, in this Bengali Asian Indian population of eastern part of India, the prevalence of $\mathrm{CHD}$ in blood group $\mathrm{O}$ is invariably higher than in all other ABO blood groups, but Whincup et al. [10] from England and from other parts of Europe [18, 19] or USA [12], found that frequency of A blood group was more than any other $\mathrm{ABO}$ blood groups in CHD patients.

In the analyses of the relation between the $\mathrm{ABO}$ blood group and major cardiovascular risk factors the only association of note was that $\mathrm{O}$ blood group, probably by association with lower HDL-c levels, smoking habit, and family history, significantly increases the risk of $\mathrm{CHD}$, and contributes substantially to the incidence of CHD in the studied populations. In the two previous reports $[20,21]$, only association was found between blood group A and serum total cholesterol concentration among the major cardiovascular risk factors. The higher concentrations of HDL-c in subjects of blood group $\mathrm{AB}$ seemed to contribute to the protective role of $\mathrm{CHD}$ events in subjects of controls group.

The limitation of the present study is the lack of followup data, mostly due to the lack of patient compliance. We have also a limitation in our study regarding the estimation of the extent and burden of atherosclerosis by doing coronary angiography and multidetector row computed tomography.

\section{Conclusion}

The racial and ethnic distribution of blood groups and size of sample are important factors for predicting the $\mathrm{CHD}$ risk. Blood type needs to be considered together with other risk factors to understand the individual patient's risk. The identification of genetic and environmental factors among racial and ethnic groups should offer some insights into the observed epidemiological data and advance opportunities to better understand the control and development of CHD.

\section{Authors' Contribution}

Santanu Biswas and Pradip K. Ghoshal contributed equally to this work.

\section{Acknowledgments}

Authors are grateful to the staff of Department of Cardiology, N.R.S. Medical College \& Hospital, Kolkata, India, for their cooperation during the sample collection. The authors acknowledge Mr. Ranjit Kumar Das for their kind help in this work.

\section{References}

[1] A. V. Hoffbrand, Post Graduate Haematology, Heinemann Professional, London, U. K, 2nd edition, 1981.

[2] P. L. Molison, Blood Transfusion in Clinical Medicine, Blackwell Scientific Publication, Oxford, UK, 6th edition, 1979.

[3] H. Egawa, F. Oike, L. Buhler et al., "Impact of recipient age on outcome of ABO-incompatible living-donor liver transplantation," Transplantation, vol. 77, no. 3, pp. 403-411, 2004.

[4] A. Shamim, M. A. Hafeez, and M. M. Ahmad, "ABO and Rh blood groups I: markers of cardiovascular risk and association with lipids and other related risk co variables in a Pakistani population," Proceedings of the Pakistan Academy of Sciences, vol. 39, pp. 47-66, 2002.

[5] M. Komar-Szymborska, J. Szymborski, A. Sleboda, M. Bajkacz, and E. Cioch, "RH and $\mathrm{ABO}$ incompatibility in newborns treated in a pediatric hospital," Wiadomosci Lekarskie, vol. 46, no. 17-18, pp. 644-650, 1993.

[6] D. Lester, "Predicting suicide in nations," Archives of Suicide Research, vol. 9, no. 2, pp. 219-223, 2005. 
[7] H. O. Hein, P. Suadicani, and F. Gyntelberg, "The Lewis blood group-a new genetic marker of obesity," International Journal of Obesity and Related Metabolic Disorders, vol. 29, no. 5, pp. 540-542, 2005.

[8] D. Platt, W. Muhlberg, L. Kiehl, and R. Schmitt-Ruth, "ABO blood group system, age, sex, risk factors and cardiac infarction," Archives of Gerontology and Geriatrics, vol. 4, no. 3, pp. 241-249, 1985.

[9] M. H. Fox, L. S. Webber, T. F. Thurmon, and G. S. Berenson, "ABO blood group associations with cardiovascular risk factor variables," Human Biology, vol. 58, no. 4, pp. 549-584, 1986.

[10] P. H. Whincup, D. G. Cook, A. N. Phillips, and A. G. Shaper, "ABO blood group and ischaemic heart disease in British men," British Medical Journal, vol. 300, no. 6741, pp. 1679-1682, 1990.

[11] Z. Tarján, M. Tonelli, J. Duba, and A. Zorándi, "Correlation between $\mathrm{ABO}$ and $\mathrm{Rh}$ blood groups, serum cholesterol and ischemic heart disease in patients undergoing coronarography," Orvosi Hetilap, vol. 136, no. 15, pp. 767-769, 1995.

[12] R. C. Ellison, Y. Zhang, R. H. Myers, J. L. Swanson, M. Higgins, and J. Eckfeldt, "Lewis blood group phenotype as an independent risk factor for coronary heart disease," American Journal of Cardiology, vol. 83, no. 3, pp. 345-348, 1999.

[13] S. Biswas, P. K. Ghoshal, S. C. Mandal, and N. Mandal, "Association of low-density lipoprotein particle size and ratio of different lipoproteins and apolipoproteins with coronary heart disease," Journal of Cardiology, vol. 52, no. 2, pp. 118-126, 2008.

[14] H. Varley, A. H. Gowenlock, and M. Bell, Practical Clinical Biochemistry, William Heinemann Medical Books, London, UK, 1980.

[15] M. W. Strickberger, Dominance Relations and Multiple Alleles in Diploid Organisms, McMillan, NewYork, NY, USA, 2nd edition, 1976.

[16] V. M. Morelli, M. C. H. de Visser, H. L. Vos, R. M. Bertina, and F. R. Rosendaal, "ABO blood group genotypes and the risk of venous thrombosis: effect of factor V Leiden," Journal of Thrombosis and Haemostasis, vol. 3, no. 1, pp. 183-185, 2005.

[17] T. Ohira, M. Cushman, M. Y. Tsai et al., "ABO blood group, other risk factors and incidence of venous thromboembolism: the Longitudinal Investigation of Thromboembolism Etiology (LITE)," Journal of Thrombosis and Haemostasis, vol. 5, no. 7, pp. 1455-1461, 2007.

[18] T. W. Meade, J. A. Cooper, Y. Stirling, D. J. Howarth, V. Ruddock, and G. J. Miller, "Factor VIII, ABO blood group and the incidence of ischaemic heart disease," British Journal of Haematology, vol. 88, no. 3, pp. 601-607, 1994.

[19] P. M. McKeigue, M. G. Marmot, and A. M. Adelstein, "Diet and risk factors for coronary heart disease in Asians in northwest London," The Lancet, vol. 2, no. 8464, pp. 1086-1089, 1985.

[20] M. J. Langman, P. C. Elwood, J. Foote, and D. R. Ryrie, "ABO and Lewis blood-groups and serum-cholesterol," The Lancet, vol. 2, no. 7621, pp. 607-609, 1969.

[21] M. F. Oliver, H. Geizerova, R. A. Cumming, and J. A. Heady, "Serum-cholesterol and $\mathrm{ABO}$ and rhesus blood-groups," The Lancet, vol. 2, no. 7621, pp. 605-607, 1969. 

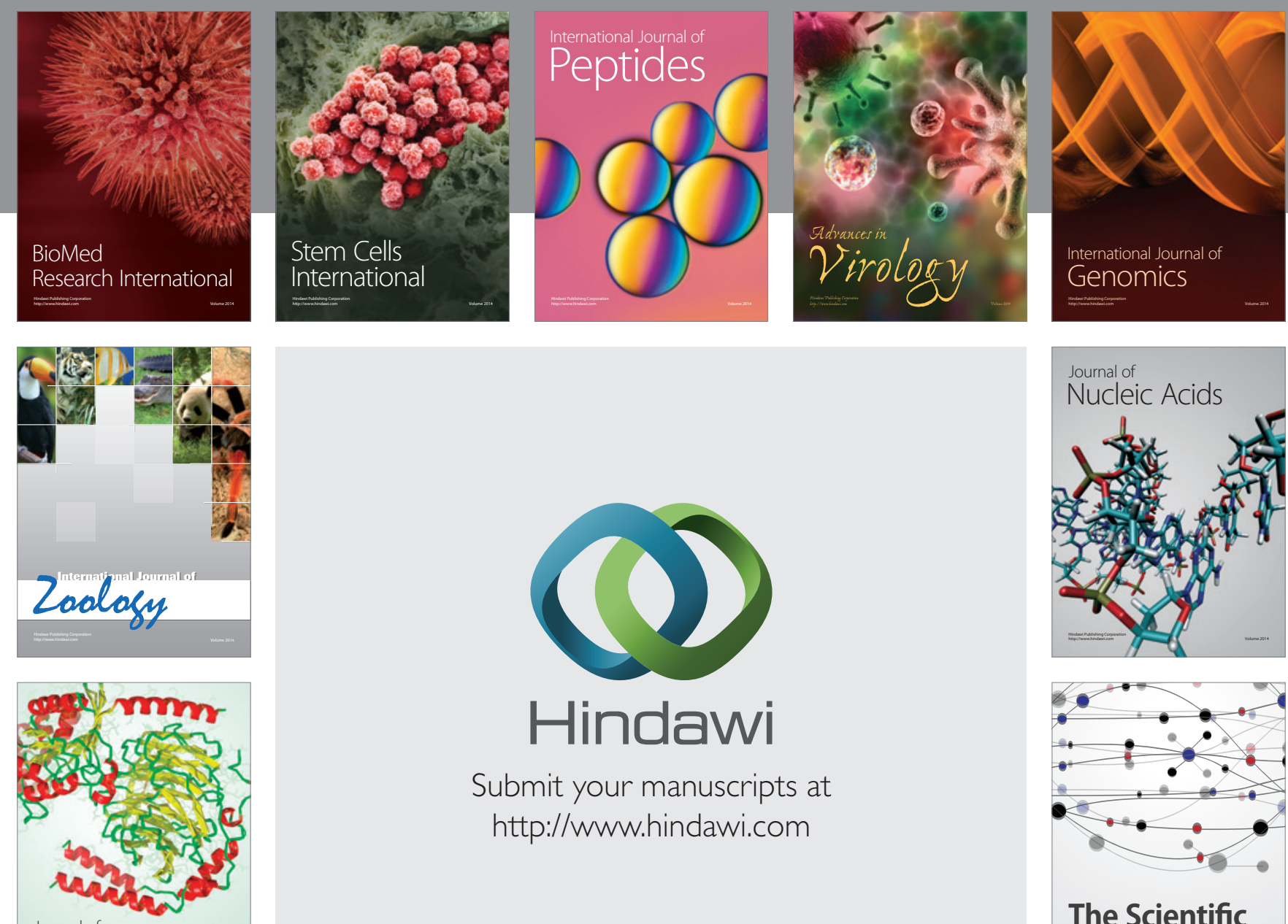

Submit your manuscripts at

http://www.hindawi.com

Journal of
Signal Transduction
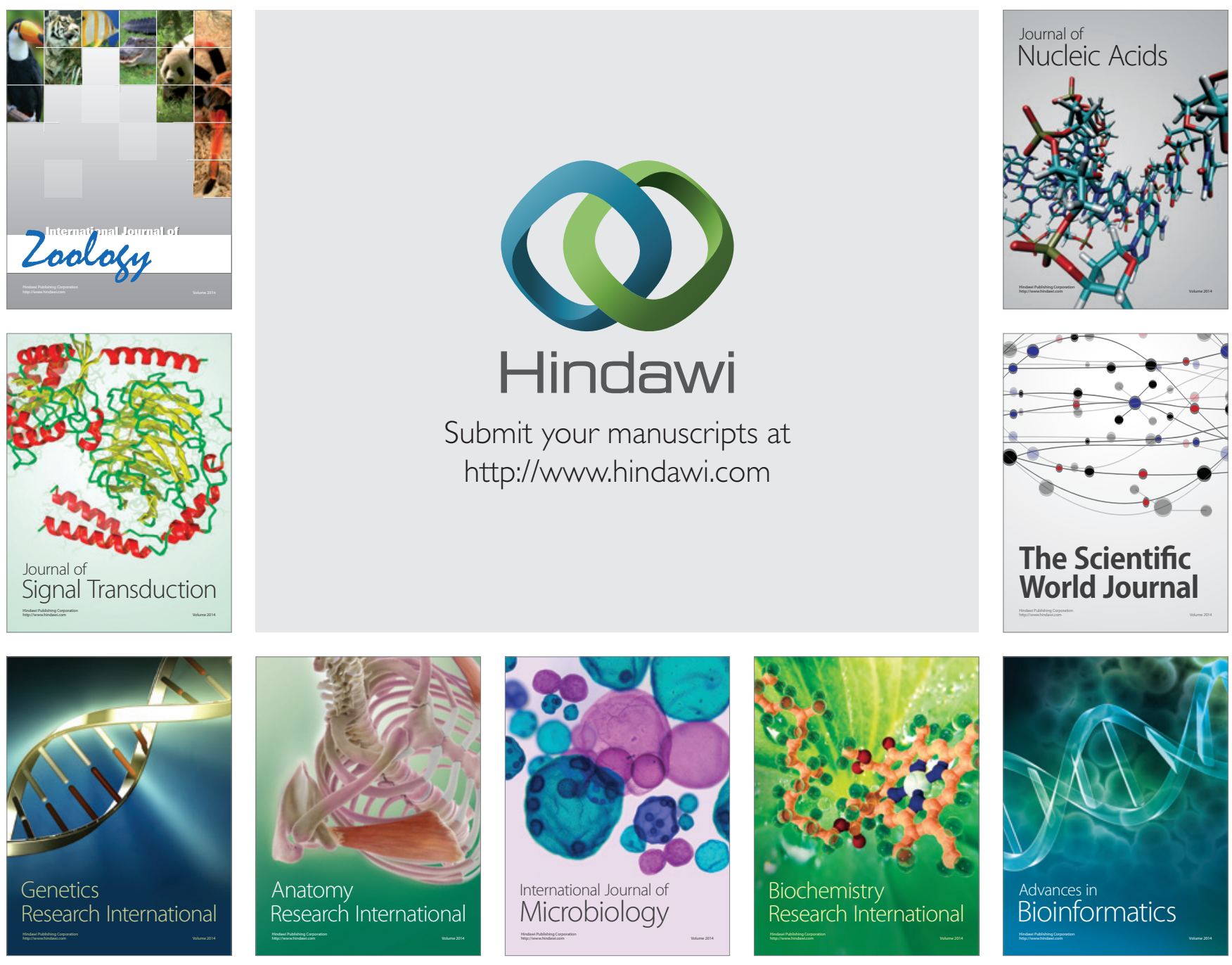

The Scientific World Journal
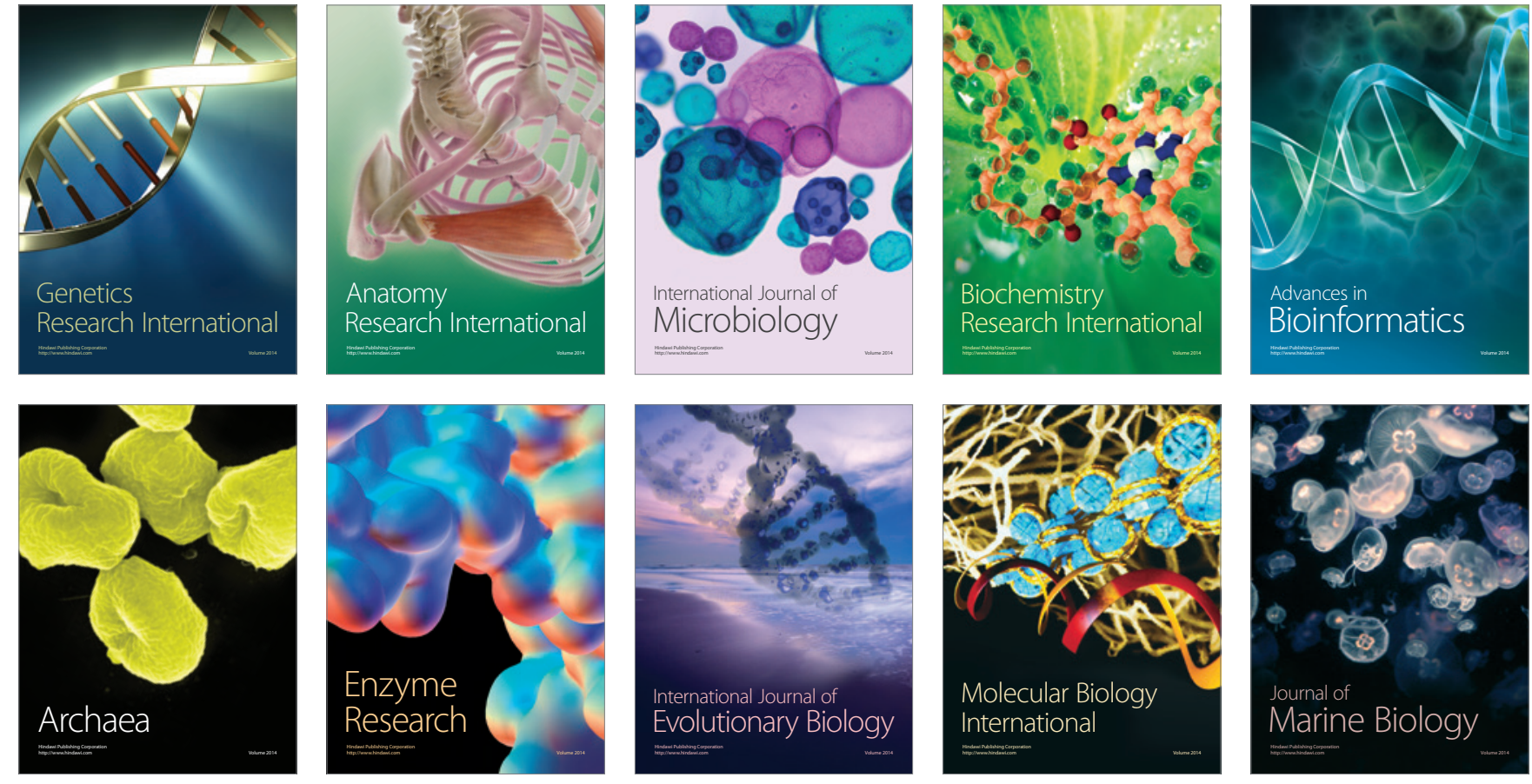